\title{
PANJANG BOBOT DAN KOMPOSISI MAKANAN IKAN BUNTAL PISANG Lagocephalus lunaris (TETRAODONTIDAE) DI SUNGAI MUSI, SUMATERA SELATAN
}

\author{
Ni Komang Suryati ${ }^{1)}$ dan Eko Prianto1) \\ 1) Peneliti pada Balai Riset Perikanan Perairan Umum, Mariana-Palembang \\ Teregristrasi I tanggal: 5 Mei 2008; Diterima setelah perbaikan tanggal: 15 Mei 2008; Disetujui terbit tanggal: 26 Mei 2008
}

\begin{abstract}
ABSTRAK
Riset mengenai biologi ikan buntal pisang (Lagocephalus lunaris) dilakukan tahun 2007 di Sungai Musi. Tujuan riset yaitu untuk mengetahui karakteristik biologi yang meliputi distribusi panjang dan bobot ikan, hubungan panjang bobot, komposisi jenis makanan (menggunakan index of preponderance). Hasil penelitian menunjukkan hubungan antara ukuran panjang dan bobot tubuh Ikan buntal pisang (Lagocephalus lunaris) menunjukkan allometrik negatif $(b<3)$ yang berarti pertambahan panjang lebih cepat daripada pertambahan bobot tubuh. Ikan buntal pisang (Lagocephalus lunaris) merupakan ikan karnivor yang makanan utamanya udang kecil (Crustacea).
\end{abstract}

\section{KATAKUNCI: panjang bobot, komposisi makanan, Lagocephalus lunaris, Sungai Musi}

ABSTRACT: Length weight and food composition of Lagocephalus lunaris (Tetraodontidae) in River Musi, South Sumatera. By: Ni Komang Suryati and Eko Prianto

Research on biology of Lagocephalus lunaris was carried out in 2007 at Musi River. The purpose of the study is to know about biological characteristic such as distribution of length weight, relationship between length and weight, composition of the food (index of preponderance). The result shows that relationship between length and weight of Lagocephalus lunaris was negative allometrik $(b<3)$, it means that the increase of length was faster than weight Lagocephalus lunaris was a carnivorous which the primary food is small shrimp (Crustacea).

\section{KEYWORDS: length weight, food composition, Lagocephalus lunaris, Musi River}

\section{PENDAHULUAN}

Ikan buntal pisang (Lagocephalus lunaris) termasuk dalam famili Tetraodontidae yang penyebarannya meliputi seluruh wilayah di Indonesia. Lagocephalus lunaris atau ikan buntal pisang (Lagocephalus lunaris) ikan ini hidup di perairan estuaria, berbadan gemuk dengan sisik kecil, mata yang besar, dan lubang pada celah insang besar.

Di perairan umum, ikan buntal pisang (Lagocephalus lunaris) ditangkap dengan menggunakan setrum, tugug, dan blad. Hal ini, disebabkan oleh ukuran yang relatif kecil. Tetapi ada juga yang ditangkap dengan menggunakan jala dan jaring.

Oleh masyarakat setempat, ikan buntal pisang (Lagocephalus lunaris) jarang dijadikan sebagai ikan konsumsi, karena dagingnya beracun. Tetrodotoxin adalah racun yang ditemukan pada beberapa spesies ikan buntal pisang (Lagocephalus lunaris). Menurut Fitrial (2003), daging segar dan beberapa bagian dari tubuh ikan buntal pisang (Lagocephalus lunaris) mungkin aman dimakan dalam keadaan mentah atau dimasak. Tetapi bagian lain seperti kandung telur (ovari) (tertinggi, sebagai alat perlindungan diri dari pemangsa) dan hati yang sangat beracun, mata, kulit, saluran pencernaan, dan jeroan lain, sedang bagian daging sedikit sampai dengan tidak beracun tergantung spesies. Gejala keracunan diawali dengan rasa mual, muntah, mati rasa dalam rongga mulut, selanjutnya muncul gangguan fungsi saraf yang ditandai dengan rasa gatal pada bibir, kaki, tangan, gejala selanjutnya terjadi kelumpuhan dan kematian akibat sulit bernafas, dan serangan jantung. Gejala tersebut timbul selama 10 menit sampai dengan 3 jam setelah mengkonsumsi. Mengingat resiko yang tinggi jika ikan ini salah dalam pengolahan, maka di Jepang hanya koki-koki yang memiliki sertifikat dari Departemen Kesehatan yang diizinkan untuk mengolah ikan ini untuk dikonsumsi umum. Di Jepang, menu masakan yang mengandung ikan buntal pisang (Lagocephalus lunaris) harganya cukup mahal. Di sebuah restoran di Osaka menjual menu ikan buntal pisang (Lagocephalus lunaris) dengan harga 10.500 yen atau sekitar Rp.840.000,-.

Sebagai ikan hias, kelompok ini agak sulit ditangkarkan sehingga selama ini sumber ikan yang dijual di pasaran berasal dari penangkapan di perairan umum. Kecenderungan penangkapan ikan ini di alam 
dikhawatirkan akan mengakibatkan kepunahan. Oleh karena itu, perlu dilakukan pengelolaan sumber daya yang diharapkan akan menjaga kelestarian dari ikan tersebut.

Untuk itu, perlu dilakukan studi mengenai biologi ikan buntal pisang (Lagocephalus lunaris), khususnya di Sungai Musi sehingga diharapkan potensi ikan ini dapat dimanfaatkan secara optimum dengan tetap menjaga kelestarian.

\section{BAHAN DAN METODE}

Penelitian dilakukan di Sungai Musi pada tahun 2007 (Gambar 1). Penentuan stasiun dengan menggunakan purposive sampling.

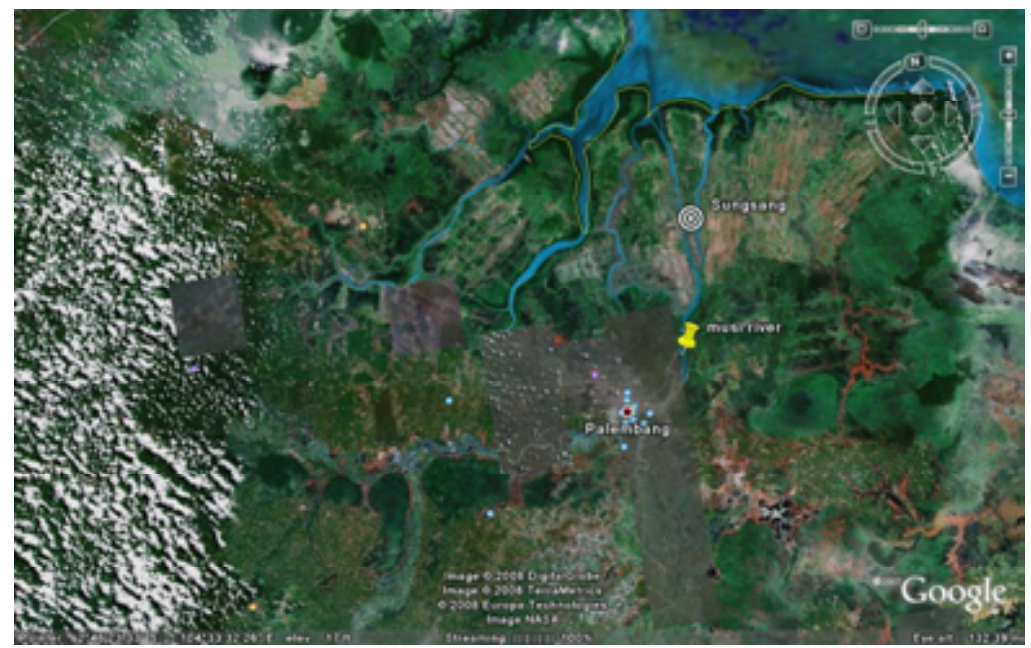

Gambar 1. Lokasi penelitian.

Figure 1. The location of research.

Sources: www.googleearth.com

Contoh ikan dikumpulkan dari hasil tangkapan nelayan dan selanjutnya ikan diawetkan dengan menggunakan formalin $10 \%$. Jumlah ikan contoh yang dianalisis panjang bobot 107 ekor, sedangkan untuk analisis isi saluran pencernaan hanya dilakukan pada 30 ekor ikan.

Selanjutnya, ikan dianalisis di Laboratorium Hidrobiologi Balai Riset Perikanan Perairan Umum. Parameter yang diamati meliputi identifikasi jenis ikan buntal pisang (Lagocephalus lunaris), ukuran panjang dan bobot serta kebiasaan makan.

Identifikasi spesies ikan menggunakan buku Kotellat (1993); Beaufort \& Griggs (1962). Pengukuran panjang total menggunakan penggaris baja dengan ketelitian $1 \mathrm{~mm}$ dan bobot tubuh ditimbang dengan timbangan digital sartorius dengan ketelitian 0,01 g.

Hubungan panjang bobot mengacu pada rumus (Effendi, 1997):

$$
\mathrm{W}=\mathrm{aL}^{\mathrm{b}}
$$

di mana:

$$
\mathrm{W}=\operatorname{bobot}(\mathrm{g})
$$

$$
\mathrm{L} \quad=\text { panjang }(\mathrm{cm})
$$$$
\mathrm{a}, \mathrm{b}=\text { konstanta }
$$

Nilai $b$ yang mungkin timbul $b<3, b=3$, dan $b>3$. Bila $b<3$ menunjukkan bahwa pertambahan panjang lebih cepat dari pertambahan bobot (pola pertumbuhan bersifat allometrik negatif). Bila $b=3$ menunjukkan pertambahan panjang sebanding dengan pertambahan bobot dan disebut isometrik. Bila $b>3$, maka pertambahan bobot lebih cepat dari pertambahan panjang (pola pertumbuhan bersifat allometrik positif).

Pembedahan dilakukan untuk melihat isi saluran pencernaan. Pengukuran panjang saluran pencernaan menggunakan digital caliper, kemudian isi dianalisis. Isi saluran pencernaan dievaluasi dengan menggunakan indeks bagian terbesar (index of preponderance) (Effendie, 1992):

$$
I i=\frac{V i \times O i}{\sum(V i \times O i)} x 100
$$

di mana:

$$
\begin{aligned}
& \mathrm{Ii}=\text { indeks bagian terbesar }(\text { index of } \\
& \quad \text { preponderance }) \\
& \mathrm{Vi}=\text { persentase volume satu macam makanan }
\end{aligned}
$$


Oi = persentase frekuensi satu macam makanan

\section{HASIL DAN BAHASAN}

Hasil penelitian selama tahun 2007 menunjukkan bahwa di Sungai Musi terdapat 6 spesies ikan dari family Tetraodontidae yang ditemukan di sepanjang Sungai Musi bagian hilir yaitu Lagocephalus lunaris dan Chonerhinos remotus, di daerah hulu sampai dengan tengah yaitu Tetraodon kretamensis dan Tetraodon palembangensis.
Ikan buntal pisang (Lagocephalus lunaris) atau Green rough backed puffer memiliki karakteristik yaitu D 12 sampai dengan 13 dan $A 10$ sampai dengan 11 (Gambar 2). Yang menjadi kunci identifikasi bagi spesies ini dibandingkan dengan ikan buntal pisang (Lagocephalus lunaris) lain adalah ekor yang berbentuk seperti bulan sabit (Kotelat, 1993).

Contoh ikan ini paling banyak diambil di Pulau Payung, Sungai Musi dengan alat tangkap tugug.

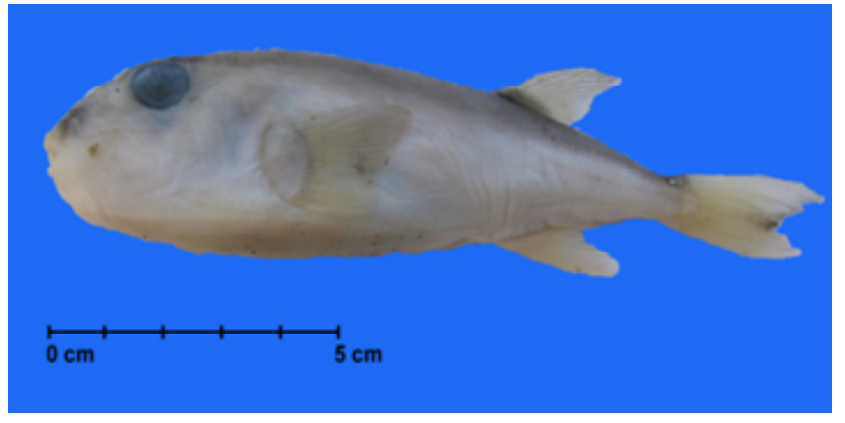

Gambar 2. Ikan buntal pisang (Lagocephalus lunaris). Sumber: Tim FIBI (2007)

Figure 2. The buntal pisang fish (Lagocephalus lunaris). Sumber: Tim FIBI (2007)

Persentase total bobot ikan yang tertangkap dapat mencapai $17,54 \%$ dari total ikan yang tertangkap.

\section{Distribusi Ukuran Panjang dan Bobot Tubuh}

Ukuran ikan contoh yang diperoleh pada penelitian ini cenderung seragam. Distribusi panjang dan bobot ikan buntal pisang (Lagocephalus lunaris) 14,5 sampai dengan $21 \mathrm{~cm}$ dan bobot tubuh antara 23 sampai dengan $68 \mathrm{~g}$.
Berdasarkan pada kisaran panjang total, jumlah ikan buntal pisang (Lagocephalus lunaris) terbanyak pada kisaran panjang 6,8 sampai dengan $7,1 \mathrm{~cm}$ dan paling sedikit pada kisaran panjang 5,6 sampai dengan 5,8 cm (Gambar 3a). Kisaran bobot menunjukkan bahwa jumlah ikan terbanyak pada kisaran 6,19 sampai dengan $7,04 \mathrm{~g}$, sedangkan jumlah ikan yang sedikit berkisar pada 9,63 sampai dengan 10,48 g (Gambar 3b).
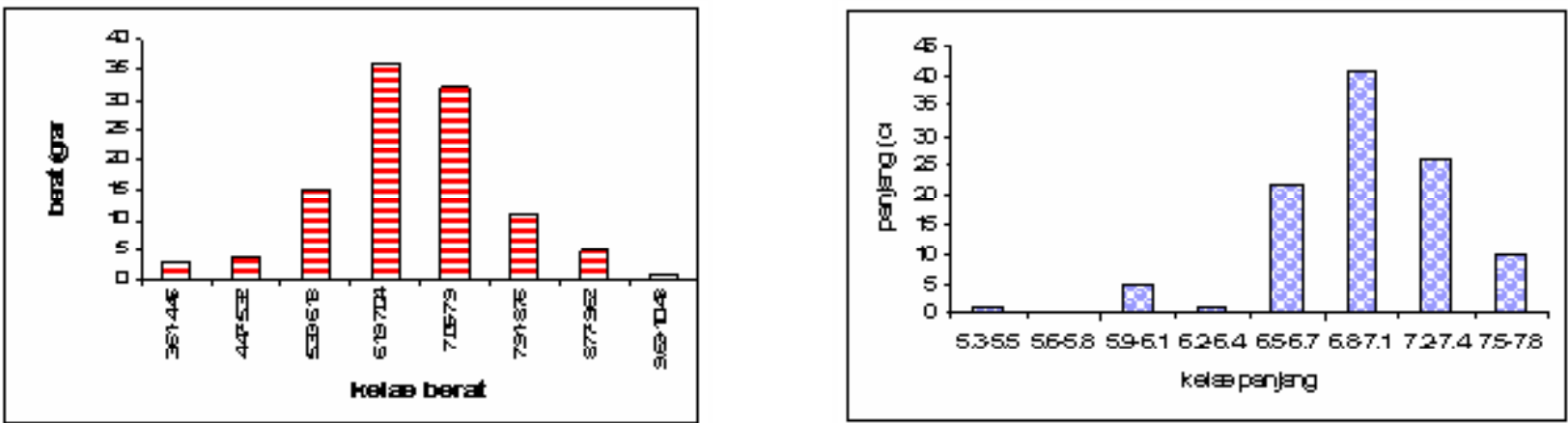

Gambar 3

Figure 3.

a) kisaran panjang dan b) kisaran bobot tubuh ikan buntal pisang (Lagocephalus lunaris). a) frequency of length and b) frequency of weight of buntal pisang fish (Lagocephalus lunaris).

\section{Hubungan Panjang Bobot}

Berdasarkan pada analisis hubungan panjang bobot ikan buntal pisang (Lagocephalus lunaris) diperoleh nilai b $1,1641(b<3)$ yang menunjukkan bahwa pola pertumbuhan ikan buntal pisang (Lagocephalus lunaris) bersifat allometrik negatif (Gambar 4). Menurut fishbase.com (2007), genus 
Lagocephalus memiliki nilai b 2,9448. Pertambahan panjang ikan buntal pisang (Lagocephalus lunaris) lebih cepat daripada pertambahan bobot tubuh.

\section{Komposisi Jenis Makanan Ikan}

Berdasarkan pada perbandingan panjang usus dengan panjang tubuh, menunjukkan bahwa ikan buntal pisang (Lagocephalus lunaris) memiliki panjang usus yang lebih pendek daripada panjang tubuh. Nilai perbandingan panjang usus dengan panjang tubuh berkisar antara 0,34 sampai dengan 0,45 atau kurang dari 1. Sehingga dapat dikatakan ikan buntal pisang
(Lagocephalus lunaris) bersifat karnivora. Ikan karnivora mempunyai usus yang lebih pendek diduga karena bahan makanan hewani lebih mudah dicerna.

Organisme yang ditemukan di dalam saluran pencernaan hanya terdiri atas udang (Crustacea) dan serasah. Dari nilai index of preponderance dan tingkat keseringan ditemukan organisme tersebut menunjukkan bahwa makanan utama ikan buntal pisang (Lagocephalus lunaris) adalah udang (Crustacea) (Gambar 5) dan makanan pelengkap yaitu serasah. Dilihat dari jenis makanan, maka ikan buntal pisang (Lagocephalus lunaris) merupakan karnivora.

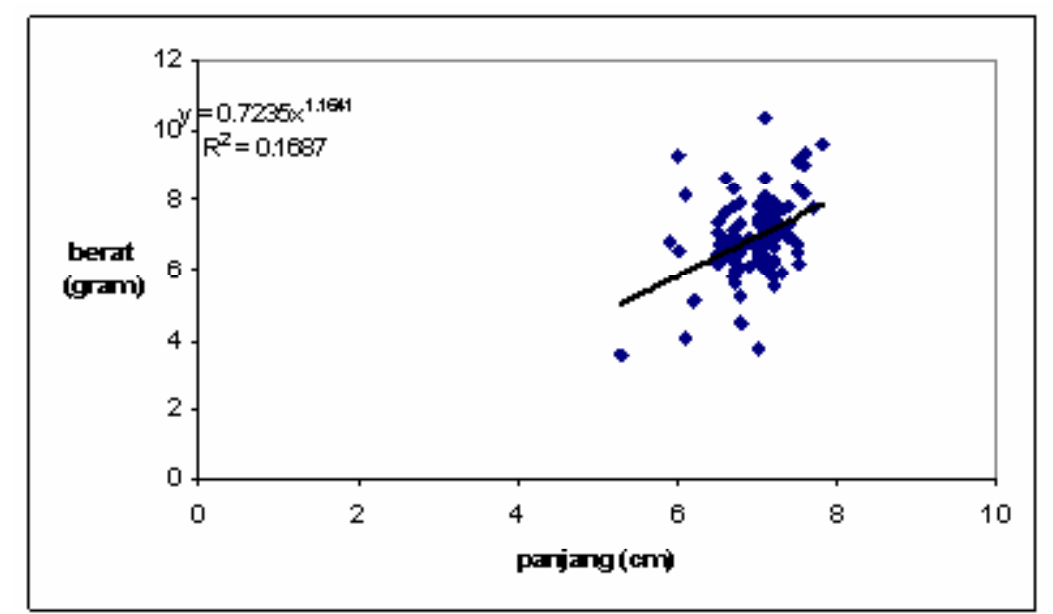

Gambar 4. Hubungan panjang bobot ikan buntal pisang (Lagocephalus lunaris).

Figure 4. Relationship between length and weight of Lagocephalus lunaris

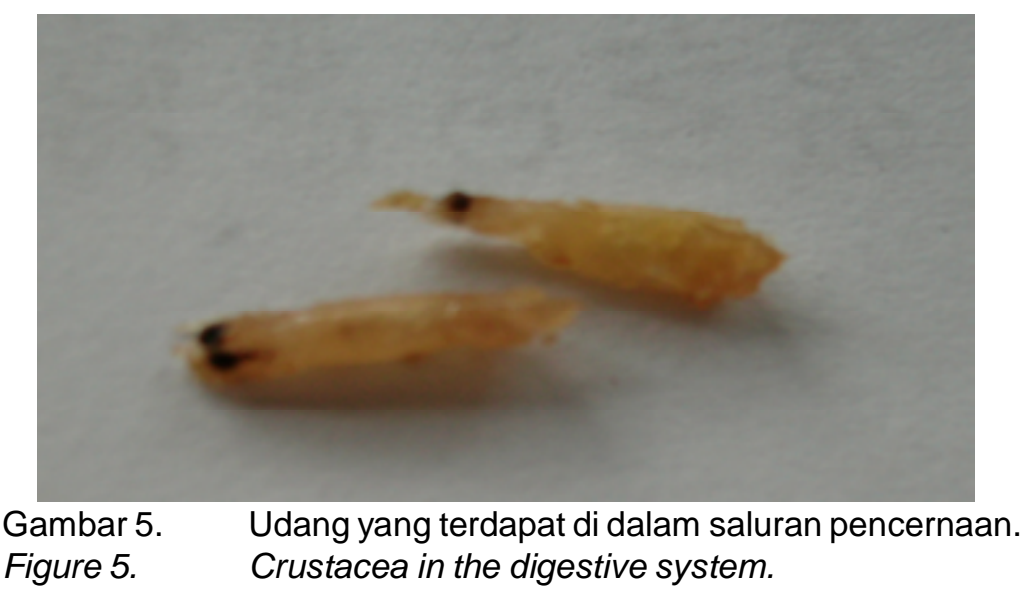

\section{Upaya Pengelolaan}

Ikan buntal pisang (Lagocephalus lunaris) berperan penting dalam keseimbangan ekologi, khususnya dalam rantai makanan di alam. Hal ini, dikarenakan ikan buntal pisang (Lagocephalus lunaris) termasuk karnivora sehingga kehadiran di alam dapat menekan populasi ikan-ikan herbivora. Jenis makanan ikan buntal pisang (Lagocephalus lunaris) yaitu berupa udang-udang kecil yang banyak terdapat di daerah mangrove, di bagian hilir Sungai Musi, sehingga untuk menjaga ketersediaan pakan bagi ikan tersebut, maka perlu dilakukan pengelolaan habitat di mana organisme tersebut berada. Oleh karena itu, kondisi mangrove yang tidak tercemar serta vegetasi yang baik akan sangat mendukung kelestarian bagi ketersediaan pakan bagi ikan buntal pisang (Lagocephalus lunaris). 
Selain itu, cara penangkapan serta selektivitas alat tangkap yang digunakan juga sangat berpengaruh terhadap kelestarian ikan tersebut.

\section{KESIMPULAN}

1. Hubungan antara ukuran panjang dan bobot tubuh ikan buntal pisang (Lagocephalus lunaris) menunjukkan allometrik negatif $(b<3)$ yang berarti pertambahan panjang lebih cepat daripada pertambahan bobot tubuh. Berdasarkan pada nilai perbandingan panjang usus dan panjang total serta jenis makanan, ikan buntal pisang (Lagocephalus lunaris) termasuk karnivor dengan makanan utama udang (Crustacea).

2. Upaya pelestarian ikan buntal pisang (Lagocephalus lunaris) dapat dilakukan dengan cara menjaga ekosistem di mana ikan tersebut hidup dan mencari makan serta perlu selektivitas dari alat tangkap yang digunakan.

\section{PERSANTUNAN}

Kegiatan dari hasil riset kajian tingkat degradasi lingkungan di perairan Sungai Musi, T. A. 2007, di Balai Riset Perikanan Perairan Umum-Mariana, Palembang. Untuk itu, penulis menyampaikan terima kasih yang sebesar-besarnya pada Dr. Husnah M.Phil., Herman, Makri, dan Budi atas segala bantuan dukungan sehingga penelitian ini dapat terlaksana.

\section{DAFTAR PUSTAKA}

Beaufort, L. F. De \& Briggs, John C. 1962. The fishes of Indo Australian Archipelago IX. Scleroparei, Hypostomidae, Pediculati, Plectognathi, Opisthomi, Discocephali, and Xenopterygii. Brill. Leiden.

Effendie, M. I. 1997. Biologi perikanan. Yayasan Pustaka Nusatama. Yogyakarta.

Effendie, M. I. 1992. Metode biologi perikanan. Yayasan Agromedia. Bogor.

Fitrial, Y. 2003. Toksin marin alami. Makalah Pribadi Pengantar ke Falsafah Sains (Program Pasca Sarjana). Institut Pertanian Bogor. Bogor.

http://fishbase.nrm.se/Summary/species Summary. php.genusname=Lagocephalus\&speciesname=lunaris( 16 Maret 2008).

Kottelat, M., A. J. Whitten, S. N. Kartikasari, \& S. Wirjoatmojo. 1993. Freshwater fishes of western Indonesia and Sulawesi (Ikan air tawar Indonesia bagian barat dan Sulawesi). Periplus EditionsEMDI Project. Jakarta.

www.Googleearth.com. (2 Maret 2008). 